\title{
Adsorption behavior of $\alpha$-cypermethrin on cork and activated carbon
}

\author{
VALENTINA F. DOMINGUES, GIUSEPPE PRIOLO, ARMINDA C. ALVES, MIGUEL F. CABRAL \\ and CRISTINA DELERUE-MATOS
}

Studies were undertaken to determine the adsorption behavior of $\alpha$-cypermethrin $[R)$ - $\alpha$-cyano-3-phenoxybenzyl(1S)-cis3-(2,2-dichlorovinyl)-2,2-dimethylcyclopropanecarboxylate, and ( $S$ )- $\alpha$-cyano-3-phenoxybenzyl (1R)-cis-3-(2,2-dichlorovinyl)-2,2dimethylcyclopropanecarboxylate] in solutions on granules of cork and activated carbon (GAC). The adsorption studies were carried out using a batch equilibrium technique. A gas chromatograph with an electron capture detector (GC-ECD) was used to analyze $\alpha$-cypermethrin after solid phase extraction with C18 disks. Physical properties including real density, pore volume, surface area and pore diameter of cork were evaluated by mercury porosimetry. Characterization of cork particles showed variations thereby indicating the highly heterogeneous structure of the material. The average surface area of cork particles was lower than that of GAC. Kinetics adsorption studies allowed the determination of the equilibrium time -24 hours for both cork (1-2 mm and 3-4 mm) and GAC. For the studied $\alpha$-cypermethrin concentration range, GAC revealed to be a better sorbent. However, adsorption parameters for equilibrium concentrations, obtained through the Langmuir and Freundlich models, showed that granulated cork 1-2 mm have the maximum amount of adsorbed $\alpha$-cypermethrin $\left(\mathrm{q}_{\mathrm{m}}\right)(303 \mu \mathrm{g} / \mathrm{g})$; followed by GAC $(186 \mu \mathrm{g} / \mathrm{g})$ and cork 3-4 mm (136 $\left.\mu \mathrm{g} / \mathrm{g}\right)$. The standard deviation (SD) values, demonstrate that Freundlich model better describes the $\alpha$-cypermethrin adsorption phenomena on GAC, while $\alpha$-cypermethrin adsorption on cork (1-2 $\mathrm{mm}$ and 3-4 $\mathrm{mm})$ is better described by the Langmuir. In view of the adsorption results obtained in this study it appears that granulated cork may be a better and a cheaper alternative to GAC for removing $\alpha$-cypermethrin from water.

Keywords: Adsorption; activated carbon; cypermethrin; cork; pesticide; pyrethroid.

\section{Introduction}

Pyrethroids are effective pesticides against a wide range of pests and are commonly used in agriculture, public health and industry. Pyrethroids are synthetic analogs of pyrethrins, which have been developed to circumvent the rapid photodegradation of pyrethrins. ${ }^{[1]}$ Pyrethroids are commonly used around the world, as successful alternatives to traditional organophosphorus insecticides, given their cost-effectiveness and lower toxicity to mammals. ${ }^{[2]}$
Among the group of pyrethroids, cypermethrin $[R)-\alpha-$ cyano-3-phenoxybenzyl (1S)-cis-3-(2,2-dichlorovinyl)-2,2dimethylcyclopropanecarboxylate and (S)- $\alpha$-cyano-3phenoxybenzyl (1R)-cis-3-(2,2-dichlorovinyl)-2,2-dimethylcyclopropanecarboxylate] was introduced in the late 1970s and has since then been used on a wide range of crops, due to its high pesticide activity. ${ }^{[3]}$ In recent years cypermethrin has been commonly used to control wohlfahrtiosis in sheep ${ }^{[4]}$ and several insect pests of cotton. ${ }^{[5-8]}$ The textile industry is one of the largest industrial producers of contaminated wastewaters. Besides the presence of unfixed dyes, pyrethroids used to preserve cotton and wool, are also present in wastewaters. The removal of pesticides such as cypermethrin from waters assumes a critical role in environmental management. Among the methods used to remove micro pollutants from wastewater, activated carbon adsorption despite its high costs has been the most widespread because of its efficiency, capacity and application on a large scale. Activated carbon has been known as 
an effective adsorbent due to its surface properties such as surface area, porosity and surface chemical properties.

During the last decades, sorption of contaminants by sorbents of natural origin has gained important credibility due to the good performance and low cost of these complex materials. Studies of pollutants removal efficiency using materials as bagasse fly ash,,${ }^{[9,10]}$ diatomaceous earth, ${ }^{[11]}$ chitosan, ${ }^{[12]}$ pinus bark, ${ }^{[13]}$ cork residues ${ }^{[14]}$ and wood chips, ${ }^{[17]}$ have recently shown the consistency and economic advantages of such alternatives. In the western Mediterranean region, and especially in the south of Portugal, cultivation of cork oak is an important economic activity. Besides the production of stoppers, the cork industry creates enormous volumes of by-products (particles of several sizes), used in part to produce calorific energy, but mainly deposed as industrial waste.

Cork has been studied to remove pollutants from environmental samples. Chubar et al. ${ }^{[15]}$ used cork biomass as sorbent for copper, zinc and nickel, and Carvalho et al. ${ }^{[16]}$ produced activated carbon from cork waste to adsorb gas components. The chemical composition of cork is described as suberin, $39 \%$; lignin $22 \%$; polysaccharides $18 \%$; extractives $15 \%$ and ash $1 \%{ }^{[18]}$ Suberin is a macromolecule of polyester-linked fatty acids, lignin is an aromatic polymer of phenylpropane units and, extractives include mainly tannins and waxes.

Based on the study of Zhou et al, ${ }^{[19]}$ which describes the partition of synthetic pyrethroids between dissolved and particulate phases, it is expected that the high lipophilicity of these xenobiotics will facilitate sorption toward carbonaceous sorbents like cork. The objective of this study was to quantify sorption of $\alpha$-cypermethrin on cork particles (Quercus suber L.) and on granulated activated carbon (GAC) as a reference material. Comparing the adsorption data to both materials may reveal the potential use of cork as a future alternative sorbent.

\section{Materials and methods}

\section{Cork}

Granulated cork from the same geographical area, and therefore with similar composition, was supplied by Amorim \& Irmãos, S.A., Portugal. Granule diameters ranged between 1-2 $\mathrm{mm}$ and 3-4 $\mathrm{mm}$.

\section{Reagents and solutions}

Norit GAC 1240 PLUS activated carbon from Norit N.V. was used. This carbon was selected because it is an acidwashed granular activated carbon, which offers good adsorption properties for water applications and a high purity level. According to the supplier's specifications it has a neutral $\mathrm{pH}$ and a particle size between 0.5 and $1.5 \mathrm{~mm}$.

$\alpha$-Cypermethrin was obtained from Riedel-de Haën. Methanol (pro-analysis grade), and n-hexane and hy- drochloric acid (High-Performance Liquid Chromatography grade) were obtained from Merck. Deionised water (conductivity $<1 \mu \mathrm{S} / \mathrm{cm}$ ) was used throughout the work. Stock solutions of $\alpha$-cypermethrin were prepared in $\mathrm{n}$ hexane $(500 \mathrm{mg} / \mathrm{L})$ and were kept in darkness at $4^{\circ} \mathrm{C}$ for up to 6 months.

\section{Apparatus}

A Chrompack 9001 chromatograph equipped with an oncolumn injector and a 63Ni Electron Capture Detector and connected to a Chrompack "Maestro" data acquisition system was employed. Chromatographic separation of the pesticide was performed on a CP-SIL 8CB WCOT column (25 $\mathrm{m} \times 0.25 \mathrm{~mm} \mathrm{i,d}, \times 0.25 \mu \mathrm{m}$ film). Nitrogen (purity $\geq 99.999$ $\%$ ) was used as both carrier (flow rate $0.5 \mathrm{~mL} / \mathrm{min}$ ) and make-up gas $(41 \mathrm{~mL} / \mathrm{min})$.

To extract the pesticide for chromatographic analysis, a MILLIPORE vacuum system connected to a DINKO (D95) vacuum pump was used. The disks for Solid Phase Extraction (SPE), with a diameter of $47 \mathrm{~mm}$ containing octadecysilica (C18), were obtained from Supelco. For sorption assays, a SBS 30 Shaker Bath with a stirrer from Stuart connected to a Julabo F70 refrigerator was used. A Quantachrome Poremaster-60 model was used for textural characterization by mercury porosimetry.

\section{Procedure}

\section{Granulated cork preparation}

The fractions with a particle diameter between 1-2 mm and 3-4 $\mathrm{mm}$ were separated and used. To remove exceeding powder, all the granulated material was washed with deionised water and dried at $105 \pm 5^{\circ} \mathrm{C}$ for 4 days.

\section{Batch isotherm experiments}

For kinetic studies, the batch technique was used. A series of $500 \mathrm{~mL}$ capacity Erlenmeyer flasks containing $200 \mathrm{~mL}$ of a $20 \mu \mathrm{g} / \mathrm{L} \alpha$-cypermethrin solution were kept in a shaker bath at $25^{\circ} \mathrm{C}$ (75 rpm). Light was excluded to prevent photodegradation.

The equilibrium adsorption experiments were conducted to obtain sorption isotherms. The adsorption capacity of cork and GAC was determined using batch experiments at $25^{\circ} \mathrm{C}$. The adsorption study of the adsorbate was achieved by varying initial concentration. Additionally, samples with pesticides and without cork or carbon were used as controls.

\section{Chromatographic analysis}

$\alpha$-Cypermethrin was extracted from aqueous solutions (obtained from isotherms and kinetics studies) using SPE. One $\mathrm{mL}$ of methanol was added to $200 \mathrm{~mL}$ of sample solution with a $\mathrm{pH} \sim 4$. This mixture was transferred to a $\mathrm{C} 18$ disk, which was conditioned with $7 \mathrm{~mL}$ methanol and $7 \mathrm{~mL}$ of 
water. After sample loading, the disk was rinsed with 10 $\mathrm{mL}$ of water. The SPE disk was dried under vacuum for 1 hour. Elution of $\alpha$-cypermethrin was performed with an adequate volume of $n$-hexane. The coefficient of variation of the extractions with $\alpha$-cypermethrin was $9 \%$.

A portion $-0.5 \mu \mathrm{L}$-were of the extracted samples were then analyzed and quantified by capillary column gas chromatography with ECD. The oven program was: initial temperature $60^{\circ} \mathrm{C}$, held for $1 \mathrm{~min}, 26^{\circ} \mathrm{C} / \mathrm{min}$ ramp to $180^{\circ} \mathrm{C}$, held for $0.19 \mathrm{~min}, 5^{\circ} \mathrm{C} / \mathrm{min}$ ramp to $230^{\circ} \mathrm{C}$ held for $0.3 \mathrm{~min}$ and finally a $7^{\circ} \mathrm{C} / \mathrm{min}$ ramp to $270^{\circ} \mathrm{C}$ held for $11 \mathrm{~min}$. The detector temperature was $310^{\circ} \mathrm{C}$.

The pesticide concentration was calculated using the external standard method, where the calibration curve was obtained with controls extracted in the same conditions as the samples. Triplicate analyses were performed for each sample. The coefficient of variation of these triplicate measurements was $8 \%$ (maximum) of area.

\section{Results and discussion}

\section{Cork characterization}

The sorbent capacity of cork is related to its surface and its ability to interact with the surrounding medium. Some physical properties like real density, pore volume, surface area and pore diameter were obtained by mercury porosimetry (Table 1). The low density of cork, obtained in this work, shows that cork particles have an inner structure with pores. However, according to Rosa et al. ${ }^{[20]}$ these hexagonal pores (the hollow cells) are inaccessible to the molecules of the contact solutions, because they seem to be closed with air inside. The cork surface area increases with the decrease of the size of cork particles. Considering the pores characteristics, the results obtained may suggest that the surface area is mostly due to the external surface.

The cork surface area is lower than that reported for GAC by Faria et al. ${ }^{[21]}$ (obtained by Brunaver-Emmet-Teller nitrogen adsorption method). These differences might be due to the fact that cork particles are essentially constituted of macropores while GAC has mesopores and micropores.

Table 1. Physical properties of two sizes of cork particles (1-2 and 3-4 mm) and a granulated activated carbon (GAC)

\begin{tabular}{lcccc}
\hline & $\begin{array}{c}\text { Real } \\
\text { density } \\
\left(\mathrm{g} / \mathrm{cm}^{3}\right)\end{array}$ & $\begin{array}{c}\text { Pore } \\
\text { volume } \\
\left(\mathrm{cm}^{3} / \mathrm{g}\right)\end{array}$ & $\begin{array}{c}\text { Surface } \\
\text { area } \\
\left(\mathrm{m}^{2} / \mathrm{g}\right)\end{array}$ & $\begin{array}{c}\text { Pore } \\
\text { diameter } \\
(\mu \mathrm{m})\end{array}$ \\
\hline Cork 1-2 mm & 0.18 & 2.83 & 16.3 & 1.02 \\
Cork 3-4 mm & 0.18 & 2.24 & 10.7 & 1.34 \\
GAC 0.5-1.5 mm* & & $0.367^{a}$ & 972 & \\
\hline
\end{tabular}

*Data extracted from Faria et al; obtained by Brunaver-Emmet-Teller nitrogen adsorption, where mesopores area is $125 \mathrm{~m}^{2} / \mathrm{g}$.

$\mathrm{GAC}=$ granules of cork and activated carbon.

\section{$\alpha$-Cypermethrin analysis}

The retention time of $\alpha$-cypermethrin obtained under the described conditions, was $18.2 \pm 0.1 \mathrm{~min}$. The calibration curve was obtained with five standard solutions, (within a concentrations range of $30-200 \mu \mathrm{g} / \mathrm{L}$ ), and was represented by the equation $\mathrm{A}=14852 \mathrm{C}+132827(\mathrm{~A}=$ area; $\mathrm{C}$ $=$ concentration in $\mu \mathrm{g} / \mathrm{L}$ and $\left.\mathrm{R}^{2}=0.9944\right)$.

\section{Adsorption experiments}

Kinetic studies were conducted for cork 3-4 mm and GAC to establish the time needed to reach the adsorption equilibrium. The equilibrium was reached after 20 hours for both sorbents, denoting a slightly faster equilibrium for cork (Fig. 1). After 20 hours, no significant changes in the sorbed amount were observed. An incubation period of $24 \mathrm{~h}$ was adopted for all sorbents to ensure that equilibrium was reached. For an initial pesticide concentration of $20 \mu \mathrm{g} / \mathrm{L}$, the percentage of adsorption was approximately $95 \%$, which probably makes this technology acceptable for pyrethroids removal to comply with the legal limits for wastewaters. The sorption kinetics of cork and GAC correspond to the $\mathrm{L}$ type in the classification proposed by Giles et $\mathrm{a}^{[22]}$, which means that as the adsorption sites are being occupied, it becomes increasingly more difficult for adsorbate molecules to find vacant sites.

The adsorption data was compared to Langmuir and Freundlich theoretical models. Langmuir applicability was tested with Equation 1.

$$
\mathrm{q}=\frac{\mathrm{C}_{\mathrm{eq}} \mathrm{q}_{\mathrm{m}} \mathrm{K}_{\mathrm{L}}}{1+\mathrm{K}_{\mathrm{L}} \mathrm{C}_{\mathrm{eq}}}
$$

where, $\mathrm{q}$ is the adsorbed pesticide onto cork or $\operatorname{GAC}(\mu \mathrm{g} / \mathrm{g})$, $\mathrm{C}_{\mathrm{eq}}$ is the pesticide equilibrium concentration $(\mu \mathrm{g} / \mathrm{L}), \mathrm{q}_{\mathrm{m}}$ is the monolayer capacity $(\mu \mathrm{g} / \mathrm{g})$ and $\mathrm{K}_{L}(\mathrm{~L} / \mu \mathrm{g})$ is the Langmuir constant.

The Freundlich applicability was tested with Equation 2:

$$
\mathrm{q}=\mathrm{K}_{\mathrm{F}} \mathrm{C}_{\mathrm{eq}}^{\mathrm{l} / \mathrm{n}}
$$

where $\mathrm{K}_{\mathrm{F}}$ is the constant of the Freundlich equation $(\mathrm{L} / \mu \mathrm{g})$ and $\mathrm{n}$ is the Freundlich isotherm index.

The best-fitting curves through the experimental data were calculated by a computed regression with the SPSS program, according to the Langmuir and Freundlich equations. Cork and GAC isotherms data are represented for both models (Fig. 2). The range of pesticide concentrations used to fit the isotherm models were thought to reproduce the low values expected to appear in real-world systems.

The L-shaped isotherms show that GAC and cork 1$2 \mathrm{~mm}$ had a high affinity for $\alpha$-cypermethrin (Fig. 2). Furthermore, for lower equilibrium concentrations (e.g. Ceq $=5 \mu \mathrm{g} / \mathrm{L}) \mathrm{GAC}$ is more efficient than cork particles $1-$ $2 \mathrm{~mm}$. These results are conditioned by the concentration range used in this study. The adsorption parameters for higher equilibrium concentrations, obtained through 


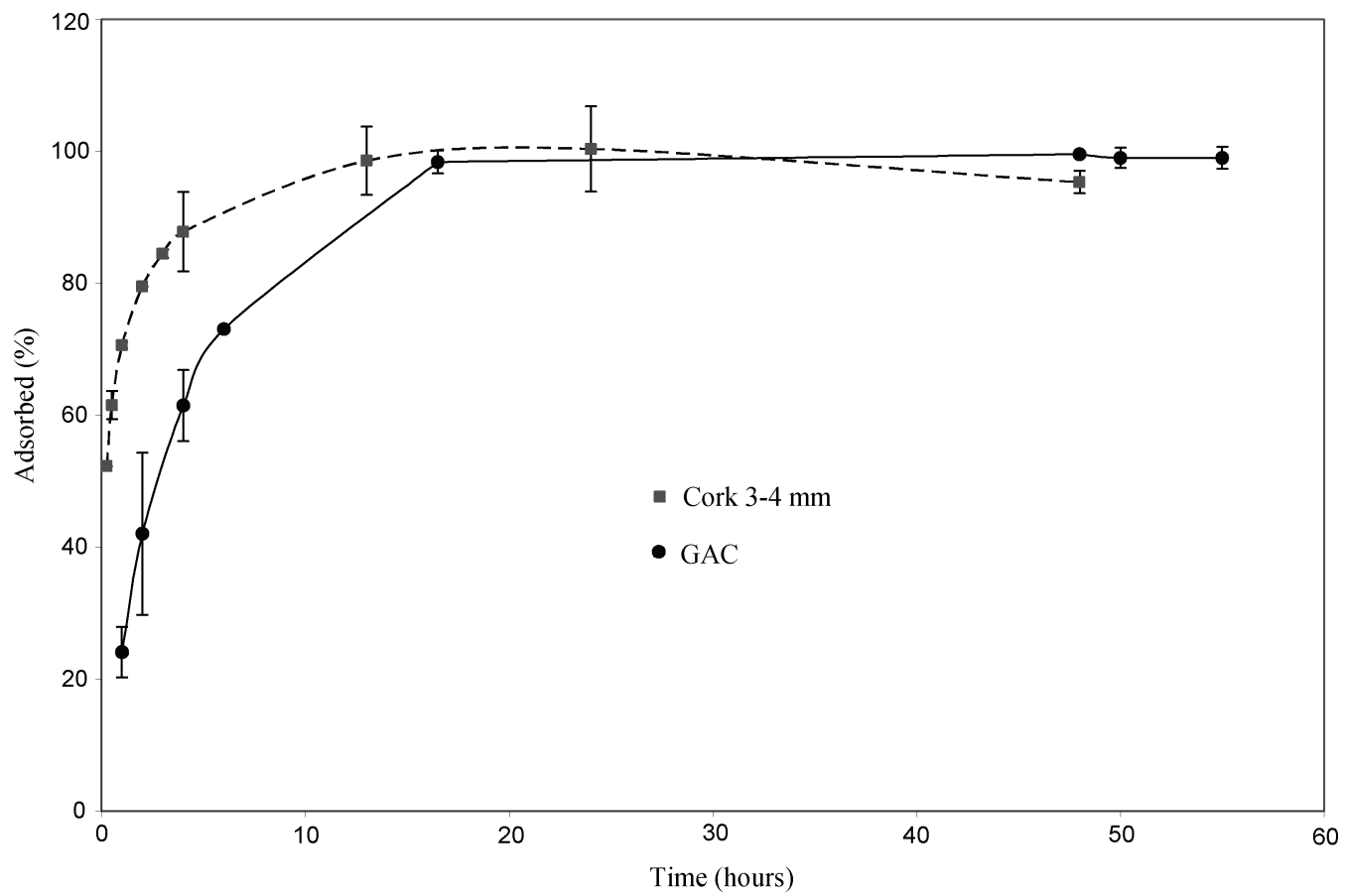

Fig. 1. Adsorption kinetics of $\alpha$-cypermethrin on cork 3-4 $\mathrm{mm}(\mathbf{\square})$ and granuleted of cork and granulated activated carbon (GAC) (•) at $25^{\circ} \mathrm{C}$, with an initial concentration of $20 \mu \mathrm{g} / \mathrm{L}$.

the Langmuir and Freundlich models (Table 2) showed however that granulated cork $1-2 \mathrm{~mm}$ have the maximum amount of adsorbed $\alpha$-cypermethrin $\left(\mathrm{q}_{\mathrm{m}}\right)(303 \mu \mathrm{g} /)$; followed by GAC $(186 \mu \mathrm{g} / \mathrm{g})$ and cork $3-4 \mathrm{~mm}(136 \mu \mathrm{g} / \mathrm{g})$.
Furthermore the Freundlich equation predicts that the pesticide concentration on the adsorbent will increase with the increasing of pesticide concentration in the solution. Moreover the SD values (Table 2), demonstrate that Freundlich

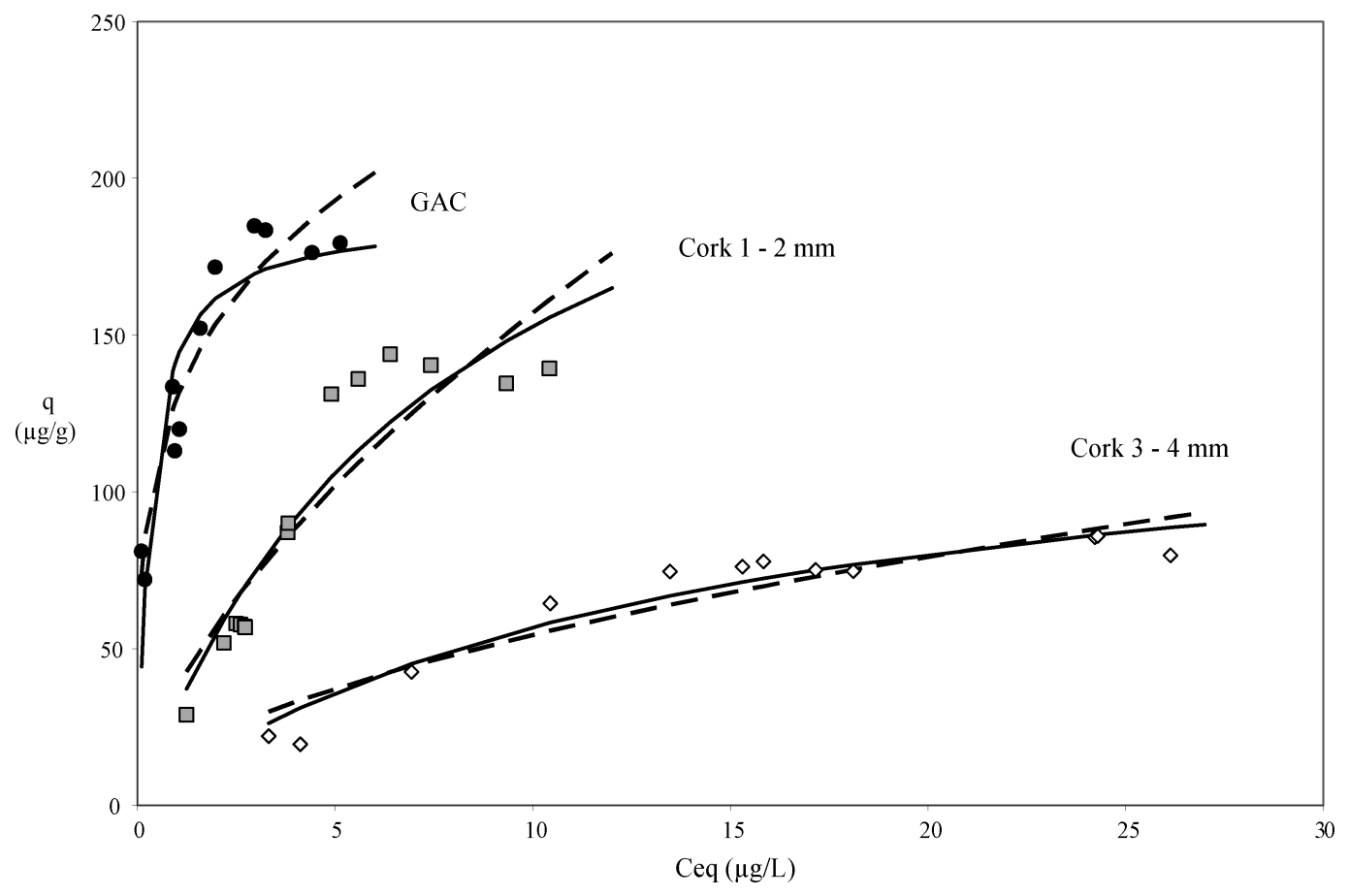

Fig. 2. $\alpha$-Cypermethrin adsorption isotherms on granules of cork and activated carbon (GAC) (•), cork 1-2 mm ( $\square$ ) and 3-4 mm ( $\Pi$ ) at $25^{\circ} \mathrm{C}$. Langmuir ( $(-)$ and Freundlich (...) models are represented. 
Table 2. Langmuir and Freundlich parameters for cork 3-4 mm, cork 1-2 mm and granulated activated carbon (GAC) obtained for $\alpha$-cypermethrin adsorption

\begin{tabular}{|c|c|c|c|c|c|c|c|}
\hline \multirow[b]{2}{*}{ Adsorbents } & \multicolumn{3}{|c|}{ Langmuir } & \multirow[b]{2}{*}{$N^{b}$} & \multicolumn{3}{|c|}{ Freundlich } \\
\hline & $q_{m}(\mu g / g)$ & $K_{L}(L / \mu g)$ & $S D^{a}$ & & $K_{F}(L / \mu g)$ & $n$ & $S D$ \\
\hline Cork 3-4 mm & $136 \pm 16$ & $0.07 \pm 0.02$ & 6 & 12 & $16 \pm 4$ & $1.8 \pm 0.3$ & 8 \\
\hline Cork $1-2 \mathrm{~mm}$ & $303 \pm 58$ & $0.11 \pm 0.03$ & 13 & 14 & $35 \pm 5$ & $1.5 \pm 0.2$ & 15 \\
\hline GAC & $186 \pm 12$ & $3 \pm 1$ & 18 & 11 & $131 \pm 5$ & $4.2 \pm 0.7$ & 13 \\
\hline
\end{tabular}

${ }^{a} \mathrm{SD}=\sqrt{\frac{\sum_{\mathrm{i}=1}^{\mathrm{N}}\left(\mathrm{q}-\mathrm{q}^{\text {calc }}\right)^{2}}{\mathrm{~N}-1}},{ }^{\mathrm{b}}$ Number of data points in isotherm.

model $(\mathrm{SD}=13)$ better describes the $\alpha$-cypermethrin adsorption phenomena on GAC than the Langmuir model $(\mathrm{SD}=18)$ while $\alpha$-cypermethrin adsorption on cork $(1-2$ $\mathrm{mm}$ and 3-4 $\mathrm{mm}$ ) is better described by the Langmuir model (respectively $\mathrm{SD}=13$ and $\mathrm{SD}=6$ ).

The differences in $\alpha$-cypermethrin uptakes for the two sizes of cork granules may be explained almost entirely by the differences in superficial surface available, given the identical chemical properties for both cork granulates. Nonetheless it is important to consider the chemical composition of the organic fraction of an adsorbent. Zhou et al. ${ }^{[19]}$ found that the humic acid fraction of soils, most aromatic, had the highest sorptive capacity for pyrethroids. Wiegand et al. ${ }^{[24]}$ studied the natural organic matters (NOMs) and a synthetic matter on Daphnia magna and showed some ability of NOMs to mitigate effects of cypermethrin. For cork, the chemical composition has been described as containing a high percentage of aromatic molecules, essentially due to the suberine molecule. Concluding, it is expected that the aromatic domain of cork, suberin, has the capacity to mitigate environmental effects of this pesticide. Considering the cork structure/chemical composition and the hydrophobic characteristics of the pyrethroids ${ }^{[23]}$, it is unlikely to find a natural sorbent for pyrethroid removal from water with such good capacity as cork.

\section{Conclusions}

The combustion of cork waste is frequently used in cork processing plants to obtain energy. Still, cork industrial byproducts are important resources to be explored with potential economic advantages. Granulated cork is structurally a highly heterogeneous material, consisting of macropores, with an extremely low surface area (about $16 \mathrm{~m}^{2} / \mathrm{g}$ ) when compared with the total area of the mesoporos of activated carbon $\left(125 \mathrm{~m}^{2} / \mathrm{g}\right)$. In this study, the comparison of adsorption data from different cork granule sizes showed an increase of the surface area with the decrease of the granule size which may signify that the external area plays an important role in the sorption process.

Kinetics adsorption results from batch experiments showed that 24 hours are necessary to reach equilibrium, both for cork and activated carbon. Equilibrium isotherms, performed in a limited concentration range simulating the pesticide concentrations found in the environment, proved, as expected, that $\alpha$-cypermethrin, had a high affinity to the sorbents, especially for cork with lower granule size (1-2 $\mathrm{mm})$.

Even considering the limits of Langmuir's theoretical model, the maximum adsorbed amount of $\alpha$-cypermethrin into cork with $1-2 \mathrm{~mm}$ of particle diameter $(303 \mu \mathrm{g} / \mathrm{g})$ is higher than that achieved when GAC with $0.5-1.5 \mathrm{~mm}$ of particle diameter is used $(186 \mu \mathrm{g} / \mathrm{g})$. Although the use of cork particles to remove pesticides is still in the research stage, its potential use in tertiary treatment of wastewaters cannot be ignored, especially when cheap alternative solutions are required. The obtained results have demonstrated that the cork may constitute a cheap, efficient natural removing agent for $\alpha$-cypermethrin, which may be explored in the future, in large scale wastewater treatment for the textile industry.

\section{Acknowledgments}

The authors would like to thank Amorim \& Irmãos for financial support.

\section{References}

[1] Polat, H.; Erkoc, F.U.; Viran, R.; Kocak, O. Investigation of acute toxicity of beta-cypermethrin on guppies Poecilia reticulata. Chemosphere 2002, 49, 39-44.

[2] Athanassiou, C.G.; Papagregoriou, A.S.; Buchelos, C.T. Insecticidal and residual effect of three pyrethroids against Sitophilus oryzae (L.) (Coleoptera : Curculionidae) on stored wheat. J. Stored Prod. Res. 2004, 40, 289-297.

[3] Friberg-Jensen, U.; Wendt-Rasch, L.; Woin, P.; Christoffersen, K. Effects of the pyrethroid insecticide, cypermethrin, on a freshwater community studied under field conditions. I. Direct and indirect effects on abundance measures of organisms at different trophic levels. Aquat. Toxicol. 2003, 63, 357-371.

[4] Sotiraki, S.; Stefanakis, A.; Hall, M.J.R. Assessment of cypermethrin and doramectin for controlling wohlfahrtiosis in Crete. Vet. Parasitol. 2003, 116, 327-332.

[5] El Kady, H.; Devine, G.J. Insecticide resistance in Egyptian populations of the cotton whitefly, Bemisia tabaci (Hemiptera : Aleyrodidae). Pest Manag. Sci. 2003, 59, 865-871. 
[6] Matthews, G.; Wiles, T.; Baleguel, P. A survey of pesticide application in Cameroon. Crop Prot. 2003, 22, 707-714.

[7] Martin, T.; Chandre, F.; Ochou, O.G.; Vaissayre, M.; Fournier, D. Pyrethroid resistance mechanisms in the cotton bollworm Helicoverpa armigera (Lepidoptera: Noctuidae) from West Africa. Pest. Biochem. Physiol. 2002, 74, 17-26.

[8] Kranthi, K.R.; Jadhav, D.R.; Kranthi, S.; Wanjari, R.R.; Ali, S.S.; Russell, D.A. Insecticide resistance in five major insect pests of cotton in India. Crop Prot. 2002, 21, 449-460.

[9] Gupta, V.K.; Ali, I. Removal of DDD and DDDE from wastewater using bagasse fly ash, a sugar industry waste. Water Res. 2001, 35, 33-40.

[10] Sakellarides, T.M.; Albanis, T.A. A new organophosphorus insecticides removal process using fly ash. Int. J. Environ. Anal. Chem. 2000, 78, 249-262.

[11] Agdi, K.; Bouaid, A.; Esteban, A.M.; Hernando, P.F.; Azmani, A.; Camara, C. Removal of atrazine and four organophosphorus pesticides from environmental waters by diatomaceous earthremediation method. J. Environ. Monit. 2000, 2, 420-423.

[12] Wong, Y.; Szeto, Y.; Cheung, W.; McKay, G. Equilibrium studies for acid dye adsorption onto Chitosan. 2003, 19, 7888-7894.

[13] Bras, I.P.; Santos, L.; Alves, A. Organochlorine pesticides removal by pinus bark sorption. Environ. Sci. Technol. 1999, 33, 631-634.

[14] Domingues, V.; Alves, A.; Cabral, M.; Delerue-Matos, C. Sorption behavior of bifenthrin on cork. J. Chromatogr. A 2005, 1069, 127 132.

[15] Chubar, N.; Carvalho, J.R.; Correia, M.J.N. Cork biomass as biosorbent for $\mathrm{Cu}(\mathrm{II}), \mathrm{Zn}(\mathrm{II})$ and $\mathrm{Ni}(\mathrm{II})$. Colloid Surf. A-Physicochem. Eng. Asp. 2003, 230, 57-65.
[16] Carvalho, A.P.; Cardoso, B.; Pires, J.; de Carvalho, M.B. Preparation of activated carbons from cork waste by chemical activation with KOH. Carbon 2003, 41, 2873-2876.

[17] Nakanishi, A.; Tamai, M.; Kawasaki, N.; Nakamura, T.; Tanada, S. Adsorption characteristics of bisphenol A onto carbonaceous materials produced from wood chips as organic waste. J. Colloid Interface Sci. 2002, 252, 393-396.

[18] Pereira, H. Chemical-Composition and Variability of Cork from Quercus-Suber L. Wood Sci. Technol. 1988, 22, 211-218.

[19] Zhou, J.L.; Rowland, S.; Mantoura, R.F.C. Partition of Synthetic Pyrethroid Insecticides between Dissolved and Particulate Phases. Water Res. 1995, 29, 1023-1031.

[20] Rosa, M.E.; Pereira, H. The Effect of Long-Term Treatment at 100Degrees-C-150-Degrees-C on Structure, Chemical-Composition and Compression Behavior of Cork. 1994, 48, 226-232.

[21] Faria, P.; Orfão, J.; Pereira, M. Adsorption of anionic and cationic dyes on activated carbons with different surface chemistries. Water Res. 2004, 38, 2043-2052.

[22] Giles, C.H.; Macewan, T.H.; Nakhwa, S.N.; Smith, D. Studies in Adsorption .11. A System of Classification of Solution Adsorption Isotherms, and Its Use in Diagnosis of Adsorption Mechanisms and in Measurement of Specific Surface Areas of Solids. 1960, 39733993.

[23] Tomlin, C.D.S. The pesticides manual, 11 ed.; British Crop Protection Council: Farnham, U.K., 1991.

[24] Meems, N.; Steinberg, C.E.W.; Wiegand, C. Direct and interacting toxicological effects on the waterflea (Daphnia magna) by natural organic matter, synthetic humic substances and cypermethrin. Sci. Total Environ. 2004, 319, 123-136. 